\title{
Erratum to: Building Integrated Explanatory Models of Complex Biological Phenomena: From Mill's Methods to a Causal Mosaic
}

\author{
Alan Love \\ Erratum to: \\ Chapter 18 in: M. Massimi et al. (eds.), EPSA15 Selected Papers, \\ European Studies in Philosophy of Science 5, \\ https://doi.org/10.1007/978-3-319-53730-6_18
}

The chapter 'Building Integrated Explanatory Models of Complex Biological Phenomena: From Mill's Methods to a Causal Mosaic' has now been made available open access under a CC BY 4.0 license.

The updated online version of this chapter can be found at

https://doi.org/10.1007/978-3-319-53730-6_18 